\title{
Call for Papers, Issue 5/2022
}

\section{Platform Economy: Beyond the Traveled Paths}

\author{
David Dann $\cdot$ Timm Teubner $\cdot$ Sunil Wattal
}

Published online: 26 February 2021

(C) The Author(s) 2021

\section{Special Issue}

Digital services and online platforms have become pervasive in all our daily lives and facilitate a wide variety of economic and social activities. This digitization of business and society has profound implications for consumer behavior and, consequently, many industries worldwide. For example, two-sided markets have emerged as popular alternatives to traditional media channels and business models. With billions in venture capital and significant market evaluations, the platform economy's most prominent players have, in fact, entered the league of longestablished industry incumbents in their respective domains. Examples include electronic commerce (e.g., Amazon, eBay, Zalando), accommodation (e.g., Airbnb, Booking.com, ImmobilienScout24), mobility (e.g., Getaround, BlaBlaCar), online work (e.g., Upwork, Fiverr, 99designs), manual tasks (e.g., Helpling, TaskRabbit), dating (e.g., Parship, Tinder), and many more.

Platforms impact business and society in many ways. New business models such as ride- and accommodation sharing, which were inconceivable on a large scale even a few years ago, have become mainstream now. As a result of marketization and platformization of people's lives,

\footnotetext{
D. Dann $(\square)$

Institute of Information Systems and Marketing, KIT Karlsruhe Institute of Technology, Karlsruhe, Germany

e-mail: david.dann@kit.edu

T. Teubner

Einstein Center Digital Future, TU Berlin, Berlin, Germany

S. Wattal

Fox School of Business, Temple University, Philadelphia, PA, USA
}

factors such as trust and privacy have gained more prominence than ever before. Platforms' design choices and employed algorithms affect our lives in many ways as these decisions - deliberately or not - set the rules for our social and economic interactions. This leads to issues such as the potential for algorithmic bias on these platforms and certain sections of the society being disadvantaged in the long-run. What is more, the twenty-first century's human being is forced to maintain a complex online reputation. Reputational data emerge in several (platform-bound) contexts - building and maintaining this reputation as a signal of trustworthiness and enabler of transactions is associated with effort and costs.

With this Special Issue, we seek to address the implications of this digital future in view of users, platform operators, legislative bodies, citizens, and society as a whole, with a particular focus on the "less traveled paths" (see bullet list below) in this domain. A rich body of work has emerged within this field of research, but many open questions remain - and new ones are prompted literally every week. In addition, it is apparent that there exist theoretical deficits within the platform literature. We hence also call for contributions applying established theoretical perspectives to the outlined problems, advancing them, or conceiving novel ones. We therefore seek contributions focusing on - but not necessarily limited to - the following selected areas:

- Roles of users, operators, and policymakers in the context of platform governance

- Dynamics of online crowd work and data marketplaces

- Impact of artificial intelligence methods on platform economics

- Role of digital platforms in alleviating and/or exacerbating existing biases and prejudices in society 
- Societal implications of digital platforms

- Gender discrimination and pay gaps on contemporary platforms as well as countermeasures

- Fake reviews and fake user profiles in the platform economy

- Role of reputation systems as a means of self-regulation

- Role of platforms in fighting the current and future pandemics

- Impact of the "working from home" paradigm on the platform economy

- Citizen Science platforms as a means to democratize the scientific method

\section{Submission Guidelines}

Please submit your paper by 1 November 2021, via BISE's online submission system (https://www.editorialmanager. com/buis/). Please observe the instructions on manuscript formatting and length. Submission guidelines and general author guidelines are available at http://www.bise-journal. com/author_guidelines.

Each submission will be reviewed anonymously (double-blind process) by at least two referees concerning its relevance, originality, and research quality. In addition to the special issue editors, distinguished international scholars will be involved in the review process as associate editors.

\section{Schedule}

Deadline for submissions: 1 November 2021

First notification of authors: 1 January 2022

Completion of first revision: 1 March 2022

Second notification of authors: 15 April 2022

Completion of second revision: 22 May 2022

Print publication: October 2022

Funding Open Access funding enabled and organized by Projekt DEAL.

Open Access This article is licensed under a Creative Commons Attribution 4.0 International License, which permits use, sharing, adaptation, distribution and reproduction in any medium or format, as long as you give appropriate credit to the original author(s) and the source, provide a link to the Creative Commons licence, and indicate if changes were made. The images or other third party material in this article are included in the article's Creative Commons licence, unless indicated otherwise in a credit line to the material. If material is not included in the article's Creative Commons licence and your intended use is not permitted by statutory regulation or exceeds the permitted use, you will need to obtain permission directly from the copyright holder. To view a copy of this licence, visit http://creativecommons. org/licenses/by/4.0/. 